
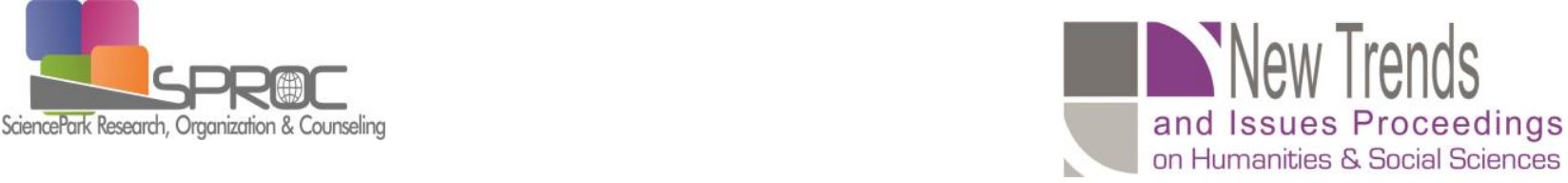

www.prosoc.eu

\title{
Pattern design preference based on symmetry
}

Reham Sanad *

Ihab Mahmoud Hanafy

Suggested Citation:

ch st st $T$ ch $w^{T}$ ch chst

st stot st

Abstract

$m$ sôt 
1. Introduction 


\section{Method}

T $m$ 


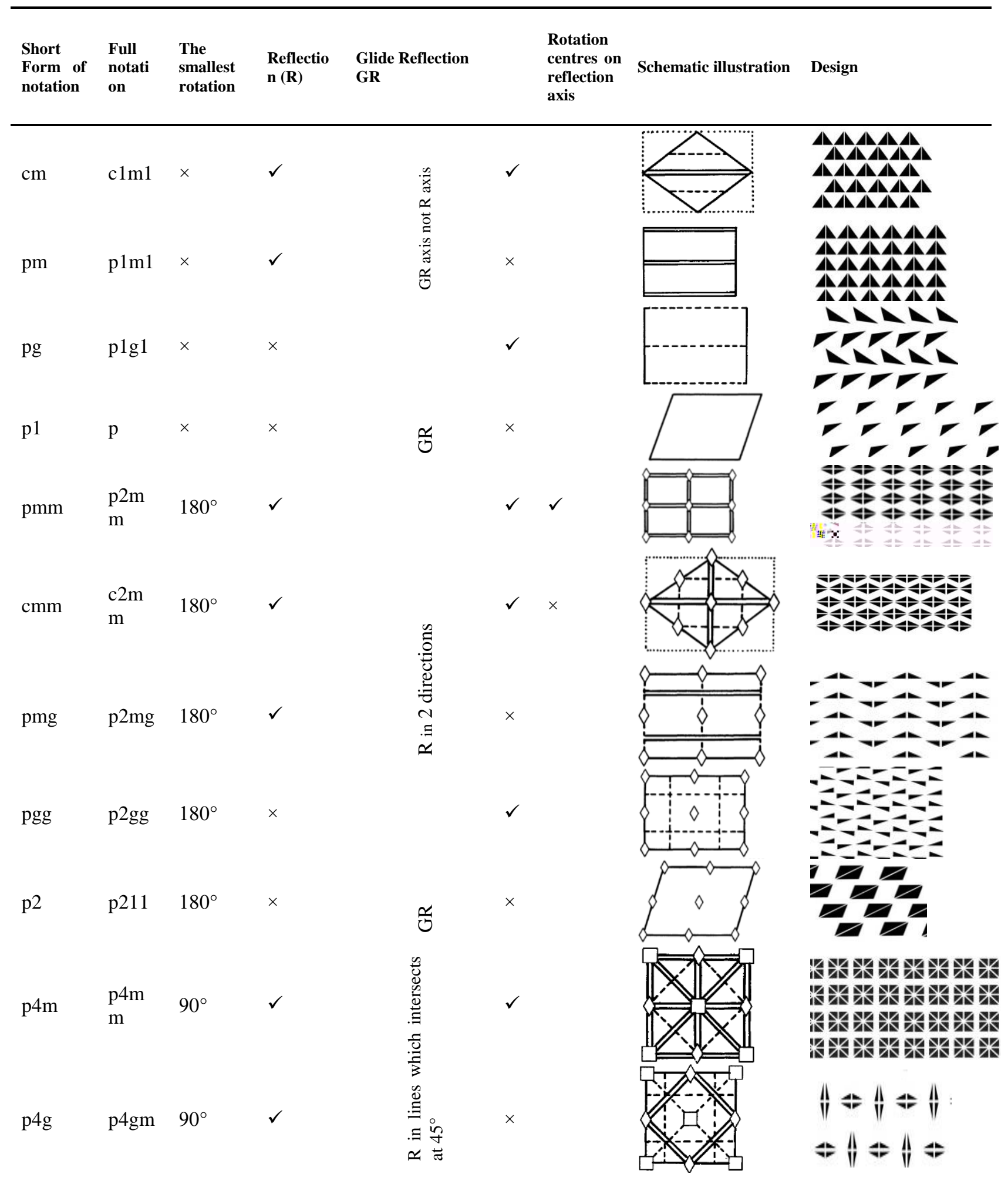




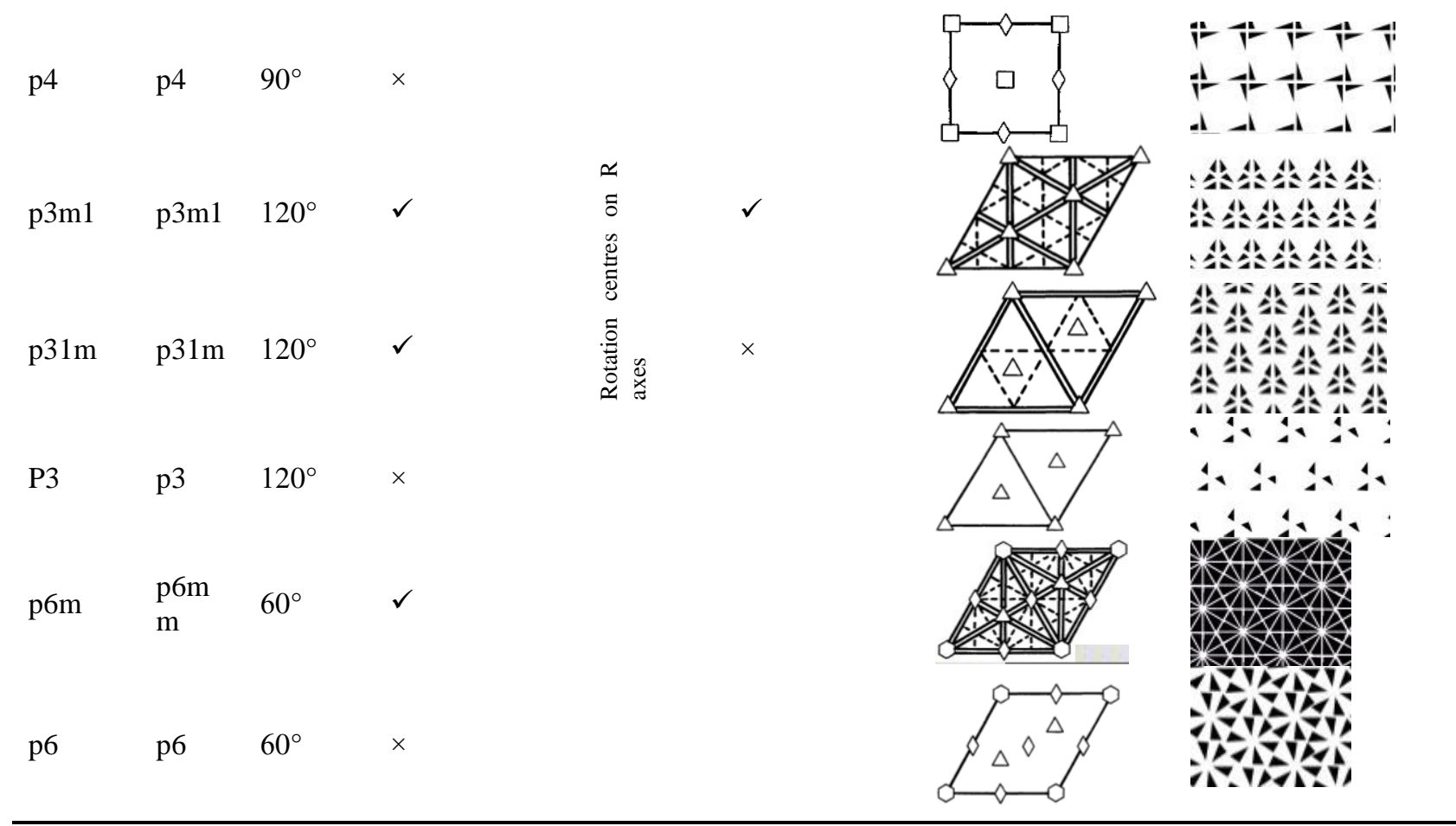

$T$ I chst

\section{Results and discussion}

sbt sft fi $m x$ st st mch fi

ch 
Tch chst

st

sहt st ch st

st $T$ ch $m$

sहt SBt

fi $m x$

st st-

fi

I mch ch 


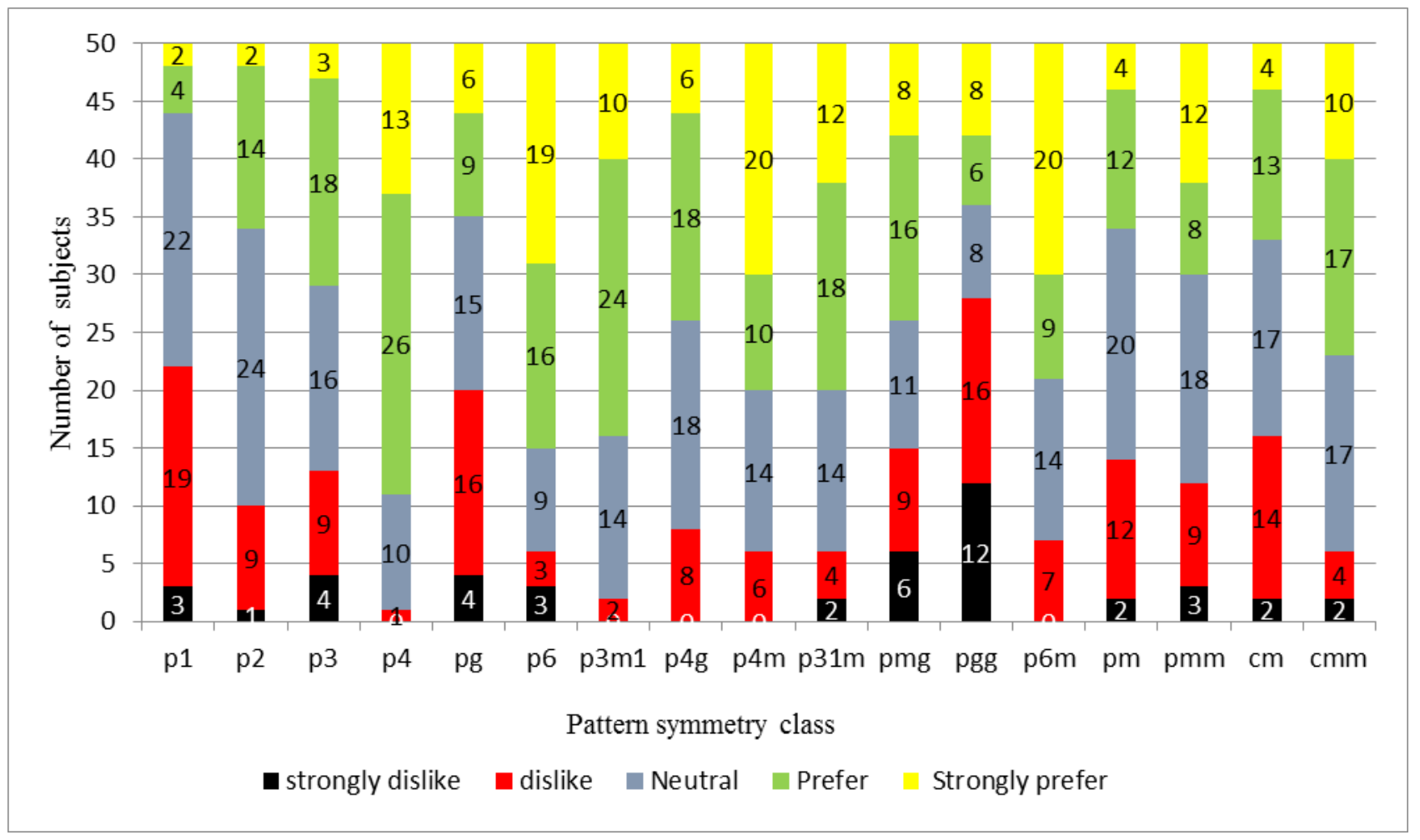


TCh chst

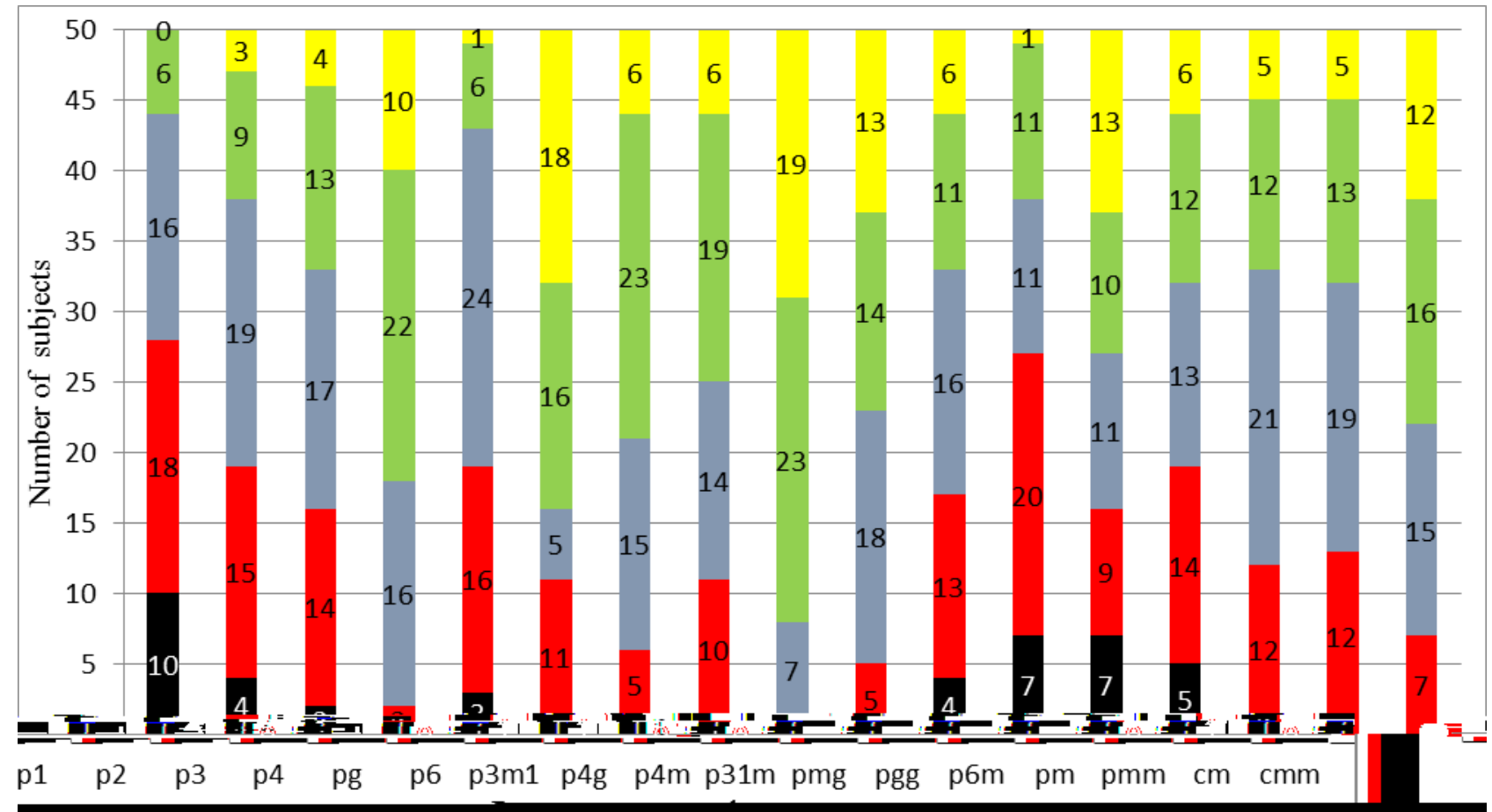

\section{Conclusions and implications}

\section{References}

Chattaraman, V., \& Rudd, N. A. (2006). Preferences for aesthetic attributes in clothing as a function of body image, body cathexis and body size. Clothing and Textiles Research Journal, 24(1), 46-61. 
Compton, N. H. (1962). Personal attributes of color and design preferences in clothing fabrics. The Journal of Psychology, 54(1), 191-195.

Crowe, D. W. (2001). Symmetries of culture. Departament of Mathematics, University of Wisconsin-Madison.

Hann, M. (2003). The Fundamentals of Pattern Structure: Part I: Woods Revisited. Journal of the Textile Institute, 94(1-2), 53-65.

Hann, M. A. (1992). Symmetry in Regular Repeating Patterns: Case Studies from Various Cultural Settings. The Journal of The Textile Institute, 83(4), 579-590.

Hann, M. A. (2003a). The Fundamentals of Pattern Structure: Part II: The Counter-change Challenge. The Journal of The Textile Institute, 94(1-2), 66-80.

Hann, M. A. (2003b). The Fundamentals of Pattern Structure: Part III: The Use of Symmetry Classification as an Analytical Tool. The Journal of The Textile Institute, 94(1-2), 81-88.

Homlong, S. (2006). The language of textiles: description and judgement on textile pattern composition.

Homlong, S. (2013). Like or dislike: aesthetic judgements on textile patterns. Paper presented at the The 2nd International Conference for Design Education Researchers, 14-17 May 2013, Oslo, Norway.

Karmel, B. Z. (1969). The effect of age, complexity, and amount of contour on pattern preferences in human infants. Journal of Experimental Child Psychology, 7(2), 339-354.

Lark-Horovitz, B. (1939). On Art Appreciation of Children: III Textile Pattern Preference Study. The Journal of Educational Research, 33(1), 7-35.

Lee, J. (1999). Impact of traditional Korean textile designs on the aesthetic evaluation of modern consumers. Journal of Consumer Studies \& Home Economics, 23(4), 239-246.

Ljungberg, L. Y., \& Edwards, K. L. (2003). Design, materials selection and marketing of successful products. Materials \& design, 24(7), 519529 .

Miranda, S. B. (1970). Visual abilities and pattern preferences of premature infants and full-term neonates. Journal of Experimental Child Psychology, 10(2), 189-205.

Paraskevopoulos, I. (1968). Symmetry, recall, and preference in relation to chronological age. Journal of Experimental Child Psychology, 6(2), 254-264.

Studd, R. (2002). The Textile Design Process. The Design Journal, 5(1), 35-49.

Washburn, D. K., \& Crowe, D. W. (1988). Symmetries of culture: Theory and practice of plane pattern analysis: University of Washington Press.

Wilson, J. (2001). Handbook of textile design: Elsevier.

Woods, H. J. (1935a). The geometrical basis of pattern design. Part I: Point and Line Symmetry in Simple Figures and Borders. Journal of the Textile Institute Transactions, 26(6), T197-T210.

Woods, H. J. (1935b). The geometrical basis of pattern design. Part II-Nets and Sateens. Journal of the Textile Institute Transactions, 26(10), T293-T308.

Woods, H. J. (1935c). The geometrical basis of pattern design. Part III-Geometrical Symmetry in Plane Patterns. Journal of the Textile Institute Transactions, 26(12), T341-T357.

Woods, H. J. (1936). The geometrical basis of pattern design. Part IV: Counterchange Symmetry in Plane Patterns. Journal of the Textile Institute Transactions, 27(12), T305-T320. 